\section{Pollution and the Persian Gulf}

SIR - The waters of the Persian Gulf are not well confined, despite the narrowness of the Strait of Hormuz, which links the Gulf to the Arabian Sea. Renewal of Gulf waters through the strait is rapid, owing to missing sills and strong thermohaline circulation. The average annual evaporation rate of the Persian Gulf is about $1.5 \mathrm{~m} \mathrm{yr}^{-1}$ (ref. 1). Estimates of relevant time scales for overturning, residence and renewal of Gulf waters range from less than one year to about four years ${ }^{1-3}$. Outflowing Gulf waters (about $3,000 \mathrm{~km}^{3} \mathrm{yr}^{-1}$ ) pass through the Strait of Hormuz as a bottom current along the deeps of the Arabian coast ${ }^{4}$. The compensating inflow $\left(0.1-0.2 \mathrm{~m} \mathrm{~s}^{-1}\right)$ occurs at the surface and mainly along the Iranian side ${ }^{2}$. The outflow from the Gulf then follows the bottom slope of the Gulf of Oman and spreads through the Arabian Sea at depths of about $200-600 \mathrm{~m}$ (ref. 5). So any environmental impact on the Gulf waters is rapidly exported to the Arabian Sea and then to the Indian Ocean.

The Gulf War is causing increased pollution of Gulf waters and its impacts cannot be assessed directly. I suggest monitoring the outflow of the Gulf waters in the Strait of

\section{Radiation doses and cancer}

SIR - In February 1990, the Soviet government allowed the release of data on the radiation doses and cancer rates to the workers in the first Soviet atom-bomb facility, near Chelyabinsk. Nikipelov et al. published in Priroda (Nature) ${ }^{1}$ the radiation doses for each year, averaged over the workforce, and the cancer rates for high- and low-dose groups. Unfortunately, they did not report the number in the workforce.

Pending release of the full data, we have deduced an estimate of the total number of workers, and hence the workforce, from the errors $\sigma$ assigned to the cancer rates $\pi$ reported by Nikipelov et al. We assume that the authors used standard statistical formulae, and obtain $n=\pi \cdot(1-\pi) / \sigma^{2}$. An entry in their Table 3, for example, which we reproduce here, gives a mortality from cancer of $5.7 \% \pm 0.6 \%$ for those workers at the reactor, employed before 1958 , who received less than $100 \mathrm{rem}$. From $\pi=0.057$ and $\sigma=0.006$, we estimate that there must have been at least 1,500 people in the workforce

Hormuz off Musandam and in the western Gulf of Oman. If immediate action is taken, the first measurements will record pre-war conditions. Subsequent shifts in levels of contamination of the outflowing waters might be used to assess the environmental impact of the war on both the Gulf waters and those of adjacent seas.

Funding for this monitoring programme should come from international agencies; management of such monitoring should be undertaken by a nongovernmental organization or a national institution in a country not involved in the war.

\section{Institut für Meerkeskunde,}

Martin Bohle-Carbonell

Troplowitzstr. 7 ,

D-2000 Hamburg 54,

Germany

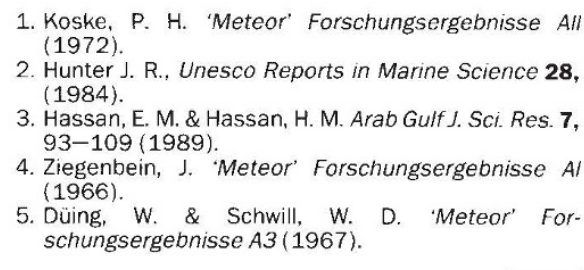

at the reactor. By combining several estimates, we determine that the number of people employed before 1958 was 2,000 at the reactor and 4,600 at the plutonium separation plant. If we allow for an average work period of five out of the 10 years, we should halve these numbers to obtain the workforce at any one time. This work period of five years may be an underestimate, even for the early years, as highly exposed workers were probably reassigned to jobs with lower exposure, rather than being dismissed, and hence remained in the listed work-force.

The collective radiation dose, then, is simply the workforce multiplied by the sum of the yearly averaged radiation doses. From Table 1 of ref. 1 , we find 260,000 person rem for the reactor, and 1.2 million person rem for the processing plant. To estimate the number of cancers that were caused by these doses, we take from the table the $3.6 \%$ difference of the cancer rates for two dose groups: greater and less than 100 rem, multiplied by the 3,100 people that we estimate received more than $100 \mathrm{rem}$. We assume that the average age of the workers was 25 years. These people would now be 65 years old, and some of their cancers would not yet

LEVEL OF CANCER MORTALITY AMONG THE EMPLOYEES OF THE CHELYABINSK FACILITY DURING 40 YEARS OF OBSERVATION

\begin{tabular}{lcccc} 
Plant & \multicolumn{2}{c}{ Total gamma dose, rem } & \multicolumn{2}{c}{ Mazimum year dose, rem } \\
& $<100$ & $>100$ & $<25$ & $>25$ \\
Reactor & $5.7 \pm 0.6$ & $9.4 \pm 1.2$ & $5.9 \pm 0.7$ & $8.7 \pm 1.1$ \\
Plutonium separation & $4.3 \pm 0.4$ & $8.1 \pm 0.6$ & $4.2 \pm 0.5$ & $7.7 \pm 0.5$ \\
Total & $4.8 \pm 0.4$ & $8.4 \pm 0.5$ & $4.9 \pm 0.4$ & $7.9 \pm 0.5$ \\
\hline
\end{tabular}

Figures are percentages of the number of people starting work before 1958 (from ref: 1). have been expressed. We therefore multiply the number of cases by a factor of 3.1 to obtain the number of cases by the end of life. (Estimate from the US statistical abstract, 1989.) This factor is sensitive to the average age of the workers; from the same data we find that the lifetime cancer mortality in the Soviet Union is a reasonable $15 \%$; less than $25 \%$ in the United States, where life expectancy is greater. We find $67 \pm 24$ lifetime cases from reactor exposures, and $242 \pm 46$ from the reprocessing facility for a total of $310 \pm 52$. This figure should be increased further by adding the smaller number of cancers among the equal number of people who accumulated less than 100 rem. Assuming that these received an average of $30 \mathrm{rem}$, and that linearity applies, another $1 / 4$ or 80 cases should probably be attributed to the lower exposures for a total of 400 . Dividing by the collective dose, we find $>3$ 'excess deaths' per 10,000 person rem.

This risk of cancer is smaller than the risk for atom-bomb survivors with similar doses (for example, the BEIR-V report ${ }^{2}$ estimates about 8 deaths per 10,000 person rem). But animal data show that spreading the doses over time can reduce the risk by a factor between 2 and 10 . The atom-bomb doses were almost instantaneous, whereas the doses at Chelyabinsk, although peaking when the workers installed radioactive equipment, were spread out in time. This comparison of the effects from Chelyabinsk and the atombombs confirms that there is some reduction factor. Stewart and Kneale have recently suggested ${ }^{3}$ that using the Hiroshima-Nagasaki cohort understates the risk because this cohort is one of healthy survivors. This argument would not apply to the Chelyabinsk cohort. Finally, the total collective dose at Chelyabinsk exceeds that for the life span study (LSS) cohort from Hiroshima and Nagasaki, and the number of people in the former cohort is less than 10,000 compared with 76,000 in the latter ${ }^{1}$. Therefore, the excess deaths from cancer will be far easier to distinguish from background.

Because the whole world is interested in these results, we call for international support to help scientists in the Soviet Union understand these issues, both with experts and with money.

ALEXANDER SHLYAKHTER RICHARD WILSON

Department of Physics,

Harvard University,

Cambridge,

Massachusetts 02138, USA

1. Nikipelov, B.V., Lizlov, A.F. \& Koshurnikova, N.A. Priroda pp 30-38 (February 1990).

2. National Research Council Committee on the Biological Effects of lonizing Radiation (BEIR V) Health Effects of Exposure to Low Levels of lonizing Radiation (National Academy, Washington DC, 1990).

3. Stewart A.M. \& Kneale, G. Hith Phys. 58, 729-735 (1990).

4. Shimizu, Y., Kato, H. \& Schull, W.J. Life Span Study Report No. 11, Part 2. (Radiation Effects Research Foundation, 1988). 